\title{
Effects of acute hypovolaemia by furosemide on tracheal transepithelial potential difference and mucus in dogs
}

\author{
N.K. Nakagawa*,\#, F. Donato-Júnior ${ }^{\#}$, C.S. Kondo", M. King ${ }^{\natural}$, J.O.C. Auler-Júnior ${ }^{+}$, P.H.N. Saldiva\# \\ G. Lorenzi-Filhos
}

Effects of acute hypovolaemia by furosemide on tracheal transepithelial potential difference and mucus in dogs. N.K. Nakagawa, F. Donato-Júnior, C.S. Kondo, M. King, J.O.C. Auler-Júnior, P.H.N. Saldiva, G. Lorenzi-Filho. C) ERS Journals Ltd 2004.

ABSTRACT: Furosemide is a potent diuretic that affects water transfer across the respiratory epithelium, which is closely related to the transepithelial potential difference (PD). Water is a critical factor that determines mucus transport; an important lung defence mechanism that removes particles and microorganisms from the respiratory system.

The aim of the present study was to investigate the acute effects of furosemide and hypovolaemia on tracheal PD and mucus properties. A total of 36 male mixed-breed dogs were submitted to anaesthesia, mechanical ventilation and haemodynamic monitoring. They were randomly assigned to three groups consisting of: a control group, a furosemide (40 $\mathrm{mg} i . v$.) + hypovolaemia group, and a furosemide (40 $\mathrm{mg} i . v)$. volume replacement group. Tracheal $P D$ and mucus samples were collected at time 0,1 and $2 \mathrm{~h}$ after intervention. Mucus properties were analysed by means of a magnetic microrheometer and in vitro mucociliary transportability on the frog palate.

Compared to controls, furosemide decreased PD to intermediate values, and only significantly when associated with hypovolaemia $(-13 \pm 5$ and $-8 \pm 2 \mathrm{mV}$, time 0 and $2 \mathrm{~h}$, respectively).

In addition to the direct effect of furosemide, these results indicate that hypovolaemia also affects ion transport in the tracheal membrane. Furosemide and hypovolemia have no acute effects on respiratory mucus properties.

Eur Respir J 2004; 24: 805-810.
*School of Physiotherapy, São Paulo City University, and Depts of ${ }^{\#}$ Pathology, ${ }^{+}$Anesthesiology, and ${ }^{\S}$ Cardiopneumology, School of Medicine, São Paulo University, São Paulo, Brazil. PPulmonary Research Group, Dept of Medicine, University of Alberta, Edmonton, AB, Canada.

Correspondence: N.K. Nakagawa, Pulmonary Defense Group, School of Medicine of São Paulo University, Room 1223, Rua Dr. Arnaldo, 455, CEPP:01246-903, São Paulo, SP, Brasil.

Fax: 551130680072

E-mail: naomikondo@uol.com.br

Keywords: Furosemide, hypovolaemia, mucociliary transport, respiratory mucus, rheology, transepithelial potential difference

Received: February 182004

Accepted after revision: June 112004

This work was supported by the São Paulo State Foundation (FAPESP) and the Medical Investigation Laboratory (LIM 5 and LIM 8) of the School of Medicine of São Paulo University.
Mucociliary transport (MCT) is an important lung protective mechanism, which removes inhaled particles and microorganisms from the respiratory system. MCT is dependant on several factors including: mucus rheological properties, ciliary activity and mucus-cilia interactions [1-3]. Mucus is a variable mixture of glycoproteins, low molecular weight ions, proteins, lipids and water [4, 5]. Water constitutes $\sim 95 \%$ of respiratory mucus [5], and is a critical factor in determining mucus clearance rate $[1,4]$. Under normal circumstances, active ion transport in the respiratory epithelium mediates the production and regulation of volume and composition of mucus [2, 4-7]. The transfer of water across the airway epithelium is closely related to the transepithelial potential difference (PD), which is considered an index of epithelium function $[1,4,7]$.

A general clinical concept suggests that systemic dehydration contributes to the production of thick, highly viscoelastic mucus or dehydrated tracheobronchial secretions that would impair MCT and lead to plugging of the airway. However, this concept is based on little scientific evidence. Previous studies involving chickens [8] and dogs [9], and the use of severe dehydration models (up to $72 \mathrm{~h}$ ), did not determine which exact mechanisms were behind these processes.

Furosemide is widely used in intensive care units, and other settings, for the reduction of plasma sodium and volume [10, 11] by inhibiting $\mathrm{NaK}(\mathrm{Cl})_{2}$ co-transporter, located at the apical membrane in the thick ascending limb of Henle's loop [12]. In the respiratory epithelium, furosemide inhibits the basolateral-to-luminal water flux coupled with chloride ion $\left(\mathrm{Cl}^{-}\right)$transport at the basolateral membrane [12-14]. Therefore, furosemide may affect the mucus water content and MCT by a direct effect on the respiratory epithelium and, indirectly, by systemic dehydration. KonDo et al. [10] observed a significant decrease in in vitro MCT after furosemide had been administered to patients undergoing mechanical ventilation (MV). On the contrary, WINTERS and YEATES [13] showed an improvement in in vivo MCT in dogs and baboons after furosemide had been administered. Based on controversial results, the present study was designed to investigate the effects of acute dehydration promoted by furosemide on tracheal PD, mucus rheology and in in vitro MCT on the frog palate in anaesthetised dogs under MV.

\section{Material and methods}

The experimental procedures and protocols for the present study on dogs were approved by the Animal Care Committee 
of the School of Medicine of São Paulo University (São Paulo, Brazil), and the National Institutes of Health guidelines were followed.

\section{Preparation of animals}

A total of 36 mixed-breed adult male dogs, $11-14 \mathrm{~kg}$ in weight were studied. Each dog had free access to water and was fasted $8 \mathrm{~h}$ before the intervention. The animal was initially anaesthetised with inhaled halothane using a facial mask, and placed in the supine position. Tracheal intubation was performed with an 8-mm sized tube. The cuff of the tracheal tube was positioned distal to the larynx. MV was initiated after intubation (Linea A Ventilator; Intermed Equipamento Médico Hospitalar, São Paulo, Brazil). An airway gas monitor (Monitor 252; Datex Instrumentarium, Helsinki, Finland) was employed throughout all the experiments. A hydrophobic heat and moisture exchanger (Pall BB100F; Pall Biomedical Products, New York, NY, USA) was placed between the "wye-connector" of the ventilator tubing and the dog to condition the inspired gases. Pulse oximetry, placed at the tongue, and ECG records were continuously monitored. A cephalic catheter was placed on the left limb, thereafter, inhaled halothane was discontinued and sodium pentobarbital $\left(10 \mathrm{mg} \cdot \mathrm{h}^{-1}\right)$ was infused to keep the animal under general anaesthesia along the study period. A central venous catheter was inserted in the right cardiac atrium via the right femoral vein to measure central venous pressure (CVP). The right femoral artery was cannulated to continuously monitor mean arterial blood pressure (MABP), and to evaluate blood gas analysis and plasma sodium. The bladder was cannulated to measure urine output and to obtain urine samples in order to estimate fractional sodium excretion. A tracheostomy was performed and PD was measured in the lower part of the opened trachea. Body temperature was maintained at $36-38^{\circ} \mathrm{C}$ with warm-water blankets and an electrical heating pad, as necessary.

\section{Study design}

All procedures previously described were completed and all animals received an infusion of $10 \mathrm{~mL} \cdot \mathrm{kg}^{-1}$ of isotonic saline solution $(0.9 \% \mathrm{NaCl})$, through peripheral venous catheterisation. The haemodynamic variables were allowed to stabilise for $30 \mathrm{~min}$ to get a steady state in all animals, after which, time 0 was set. Animals were randomly assigned to three groups ( $\mathrm{n}=12$ per group): a control group, which received no therapeutic intervention; a furosemide+hypovolaemia group $(\mathrm{F}+\mathrm{H})$, which received $40 \mathrm{mg}$ of i.v. furosemide; and a furosemide+volume replacement group $(\mathrm{F}+\mathrm{R})$, which received $40 \mathrm{mg}$ of $i . v$. furosemide and $0.9 \% \mathrm{NaCl}$ every $10 \mathrm{~min}$, to replace the volume of urine lost to ensure a normovolaemic status. The $\mathrm{F}+\mathrm{R}$ group was included in the present study in order to distinguish the effects between furosemide and hypovolaemia on PD and mucus properties. Data were recorded at time $0 \mathrm{~h}$, time $1 \mathrm{~h}$ and time $2 \mathrm{~h}$ in all groups.

\section{Data collection}

Urine output, volume infusion, fluid balance and fractional sodium excretion were determined at time $0 \mathrm{~h}$ and time $2 \mathrm{~h}$. Arterial blood samples were drawn for gas analysis at time 0 , 1 and $2 \mathrm{~h}$, and for determination of plasma sodium and haematocrit at time 0 and 2. Haemodynamic variables included in the current study were heart rate, MABP and CVP.

\section{Transepithelial potential difference}

PD technique was modified after that described by KNAUF et al. [15]. Measurements were performed across the epithelial membrane using two microelectrodes connected with $\mathrm{KCl}$ saturated agar bridges to calomel half-cells. The calomel halfcells were connected to the high input of an electrometer (Fisher Accumet 950; Fisher Scientific Co. L.L.C., Pittsburg, PA, USA), which was grounded. Due to the $\mathrm{KCl}$-saturated agar bridges, a correction for diffusion potentials was not necessary; liquid junction problems associated with perfusion methods were also avoided. The reference electrode was guided with a polyethylene catheter and placed in the s.c. space $[1,16]$ with a perfusion of $0.9 \% \mathrm{NaCl}$ solution, near the $\mathrm{dog}^{\prime}$ ' trachea. The measuring electrode was carefully placed in contact with the posterior membranous part of the lower tracheal epithelium, which is similar to previous studies [1, 17]. Prior to each experiment, the electrodes and agar bridges were connected to a common Ringer's solution bath. Whenever electrode pairs differed by $>1 \mathrm{mV}$ of $\mathrm{PD}$, the bridges were discarded. The results are presented in $\mathrm{mV}$ as mean \pm SE.

\section{Mucus collection}

Respiratory mucus samples were gently collected using a sterile suction technique [14] at times 0,1 and $2 \mathrm{~h}$ and the samples stored at $-70^{\circ} \mathrm{C}$ for further analysis, as previously described [18].

\section{Mucus analysis}

Mucus properties were assessed with two ex vivo bench tests that have been established in the literature: mucus rheological properties and in vitro MCT.

The magnetic microrheometer technique, as described by KING and MACKLEM [19] and modified by SilveIRA et al. [20], was used to measure the rheological properties of mucus. Briefly, a small steel ball was inserted into the mucus sample and its displacement, under the influence of a sinusoidal oscillating magnetic field, was measured. This ball acts as a rheological probe, because its movement is opposed by viscous and elastic forces. The mucus sample was mounted in a plexiglass container, inserted into the gap of a magnetic toroid and mounted on the stage of a projecting microscope, which was driven by a sine-wave generator. The shadow of the ball was projected onto a pair of photocells providing an electrical output in proportion to the displacement of the moving ball. The toroid current and photocell outputs were transmitted to a digital oscilloscope connected to a computer for storage and off-line processing. Measurements were made at 1 and $100 \mathrm{rad} \cdot \mathrm{s}^{-1}$ applied frequencies, and the results were expressed as logarithm of $\mathrm{G}^{*}\left(\log \mathrm{G}^{*}\right.$; dyne $\left.\cdot \mathrm{cm}^{-2}\right)$, a rigidity factor, and tangent $\delta$ ( $\tan \delta$; viscosity-to-elasticity ratio), a recoil factor.

To evaluate in vitro MCT, the ciliated frog palate preparation was used [21]. Briefly, the velocity of tracheal samples from the dogs was compared with the velocity of the autologous frog mucus, and the results were expressed in terms of relative speed (dog mucus/frog mucus). The transport velocity of mucus placed on a mucus-depleted frog palate was determined with the aid of a stereoscopical microscope 
equipped with a reticulated eyepiece. The samples were rinsed with petroleum ether to remove the oil before placement on the surface of the palate. The clearance experiments were performed at an ambient temperature, which was kept at $20^{\circ} \mathrm{C}\left(68^{\circ} \mathrm{F}\right)$. During the measurements, the frog palate was maintained inside an acrylic chamber, $100 \%$ relative humidity was provided by an ultrasonic nebuliser system using a 1:1 solution of $0.9 \% \mathrm{NaCl}$ :Ringer's solution [16, 18].

\section{Statistical analysis}

The sample size was calculated using a power of $80 \%$, with a significant level of difference of $5 \%$. Based on a previous study by the current authors [10], the desire was to detect a specified difference of 1.50 between any pair of treatment means. Statistical comparisons among groups over time were performed by two-way ANOVA for repeated measures. Differences among groups were tested by Tukey's test. Values of $\mathrm{p}<0.05$ were considered statistically significant.

\section{Results}

Mean values of all ventilatory and oxygenation parameters were stable and presented no significant differences among groups along the study period: tidal volume $(237 \pm 36 \mathrm{~mL})$, minute volume $(4.5 \pm 0.8 \mathrm{~L})$, mean airway pressure $\left(5 \pm 2 \mathrm{cmH}_{2} \mathrm{O}\right)$, positive end expiratory pressure $\left(2 \pm 1 \mathrm{cmH}_{2} \mathrm{O}\right)$, inspired oxygen fraction $(21 \%)$, pulse oxymetry $(98 \pm 1 \%)$, and end expiratory carbon dioxide fraction $(32 \pm 5 \%)$.

Table 1 summarises volume infusion, fluid balance, fractional sodium excretion and plasma sodium in the three groups. Furosemide promoted greater urine output and higher fractional sodium excretion in the $\mathrm{F}+\mathrm{H}$ and $\mathrm{F}+\mathrm{R}$ groups compared with the control group $(\mathrm{p}<0.001$, for both parameters). Fluid balance was significantly negative in the
$\mathrm{F}+\mathrm{H}$ group $(\mathrm{p}<0.001)$. Volume infusion was greater in the $\mathrm{F}+\mathrm{R}$ group compared with the control and $\mathrm{F}+\mathrm{H}$ groups $(\mathrm{p}<0.001)$. Each dog of the $\mathrm{F}+\mathrm{H}$ group lost $\sim 30 \%$ of their total intravascular volume, which resembled an acute hypovolaemia. The small but significant increase in plasma sodium observed in the $\mathrm{F}+\mathrm{R}$ group can be explained by the large volume infusion of isotonic saline solution, matching the urine losses in order to maintain normovolaemia in this group. No animal developed hyponatraemia.

Haemodynamic data and haematocrit are shown in table 2. The $\mathrm{F}+\mathrm{H}$ group presented greater heart rate $(\mathrm{p}=0.025)$ and decreased CVP as compared with control and $\mathrm{F}+\mathrm{R}$ groups $(p=0.005)$ along the study period. MABP decreased in all groups $(\mathrm{p}=0.002)$. Haematocrit showed a nonsignificant trend to be higher in the $\mathrm{F}+\mathrm{H}$ group $(\mathrm{p}=0.09)$.

Figure 1 presents the mean values of $P D \pm$ SE in the three groups. At time $0 \mathrm{~h}$, mean values of PD $(-15 \mathrm{mV})$ were similar to other findings [1]. These values remained stable up to time $2 \mathrm{~h}$ in controls. Furosemide promoted a significant decrease in PD only in the $\mathrm{F}+\mathrm{H}$ group $(\mathrm{p}=0.011)$.

Figure 2 shows the mean values of in vitro $\mathrm{MCT} \pm \mathrm{SE}$ for the three groups. MCT increased $(\mathrm{p}<0.05)$ in all groups during the study period. There were no significant differences among the groups.

Table 3 depicts the mean \pm SE rheological measurements performed at $1 \mathrm{rad} \cdot \mathrm{s}^{-1}$ and $100 \mathrm{rad} \cdot \mathrm{s}^{-1}$ in all groups. Mucus rheology was evaluated in nine dogs of each group because of the lack of sufficient sample or discoloration of the collected mucus. The rigidity factor at $1 \mathrm{rad} \cdot \mathrm{s}^{-1}$ diminished in all groups $(\mathrm{p}<0.001)$, and remained stable at $100 \mathrm{rad} \cdot \mathrm{s}^{-1}$. There were no significant differences among the groups in $\tan \delta$.

\section{Discussion}

In the present study, furosemide promoted an $\sim 30 \%$ loss of total intravascular volume and it significantly increased heart rate and decreased CVP, which resembled an acute and

Table 1.-Volume infusion, urine output, fluid balance, fractional sodium excretion and plasma sodium in control (C), furosemide+hypovolaemia $(\mathrm{F}+\mathrm{H})$ and furosemide+volume replacement $(\mathrm{F}+\mathrm{R})$ groups at time 0,1 and $2 \mathrm{~h}$

\begin{tabular}{|c|c|c|c|c|c|c|c|c|c|}
\hline \multirow[t]{2}{*}{ Time $\mathrm{h}$} & \multicolumn{3}{|c|}{$\mathrm{C}$} & \multicolumn{3}{|c|}{$\mathrm{F}+\mathrm{H}$} & \multicolumn{3}{|c|}{$\mathrm{F}+\mathrm{R}$} \\
\hline & 0 & 1 & 2 & 0 & 1 & 2 & 0 & 1 & 2 \\
\hline VI mL & $97 \pm 20$ & $91 \pm 17$ & $63 \pm 7$ & $94 \pm 5$ & $50 \pm 5$ & $38 \pm 3$ & $106 \pm 23$ & $336 \pm 70^{*}$ & $327 \pm 65^{*}$ \\
\hline $\mathrm{UO} \mathrm{mL}$ & $43 \pm 16$ & $20 \pm 5$ & $19 \pm 3$ & $54 \pm 16$ & $300 \pm 33^{*}$ & $113 \pm 20 *$ & $46 \pm 11$ & $299 \pm 70 *$ & $284 \pm 60 *$ \\
\hline FB mL & $94 \pm 21$ & $79 \pm 16$ & $56 \pm 7$ & $94 \pm 21$ & $-250 \pm 36^{*}$ & $-76 \pm 21 *$ & $106 \pm 24$ & $38 \pm 26$ & $38 \pm 15$ \\
\hline FSE $\%$ & $0.32 \pm 0.1$ & $0.19 \pm 0.1$ & $0.22 \pm 0.1$ & $0.45 \pm 0.1$ & $9.02 \pm 0.8^{*}$ & $5.82 \pm 0.8^{*}$ & $0.40 \pm 0.1$ & $8.08 \pm 1.3^{*}$ & $8.11 \pm 1.6^{*}$ \\
\hline $\mathrm{Na}^{+} \mathrm{mEq} \cdot \mathrm{L}^{-1}$ & $145 \pm 1$ & & $147 \pm 1$ & $146 \pm 1$ & & $146 \pm 1$ & $147 \pm 1$ & & $149 \pm 1 *$ \\
\hline
\end{tabular}

Data are presented as mean \pm SE, $n=12$ per group. VI: volume infusion; UO: urine output; FB: fluid balance; FSE: fractional sodium excretion; Na ${ }^{+}$: plasma sodium. \#: not measured. *: mean values were different from control $(\mathrm{p}<0.05)$.

Table 2. - Haemodynamic variables and haematocrit in control $(C)$, furosemide+hypovolaemia $(F+H)$ and furosemide + volume replacement $(\mathrm{F}+\mathrm{R})$ groups at time 0,1 and $2 \mathrm{~h}$

\begin{tabular}{|c|c|c|c|c|c|c|c|c|c|}
\hline \multirow[t]{2}{*}{ Time $\mathrm{h}$} & \multicolumn{3}{|c|}{$\mathrm{C}$} & \multicolumn{3}{|c|}{$\mathrm{F}+\mathrm{H}$} & \multicolumn{3}{|c|}{$\mathrm{F}+\mathrm{R}$} \\
\hline & 0 & 1 & 2 & 0 & 1 & 2 & 0 & 1 & 2 \\
\hline HR bpm & $127 \pm 10$ & $128 \pm 7$ & $132 \pm 5$ & $122 \pm 10$ & $156 \pm 9 *$ & $151 \pm 7 *$ & $146 \pm 11$ & $139 \pm 8$ & $127 \pm 8$ \\
\hline CVP mmHg & $7 \pm 0.3$ & $7 \pm 0.3$ & $7 \pm 0.3$ & $7 \pm 0.6$ & $5 \pm 0.6^{*}$ & $5 \pm 0.6^{*}$ & $6 \pm 0.3$ & $6 \pm 0.6$ & $7 \pm 0.3$ \\
\hline MABP $\mathrm{mmHg}$ & $119 \pm 5$ & $121 \pm 5$ & $117 \pm 7$ & $110 \pm 5$ & $128 \pm 3$ & $111 \pm 10$ & $116 \pm 3$ & $120 \pm 5$ & $109 \pm 7$ \\
\hline Ht $\%$ & $34 \pm 2$ & $\#$ & $33 \pm 2$ & $35 \pm 2$ & $\#$ & $38 \pm 2$ & $33 \pm 1$ & $\#$ & $32 \pm 1$ \\
\hline
\end{tabular}

Data are presented as mean \pm SE, $n=12$ per group. HR: heart rate; bpm: beats per minute; CVP: central venous pressure; MABP: mean arterial blood pressure; Ht: haematocrit. ${ }^{\#}$ : not measured. *: mean values were different from controls $(\mathrm{p}<0.05)$. 


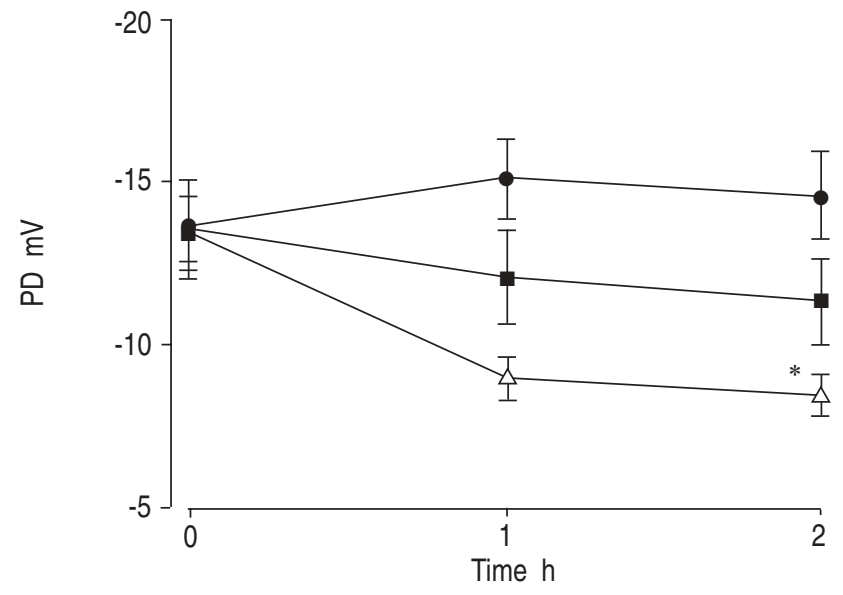

Fig. 1.-Results of the tracheal transepithelial potential difference (PD) of nine animals in the control group (-), 11 animals in the furosemide+hypovolaemia group $(\triangle)$ and 11 animals in furosemide+volume replacement group ( $\mathbf{a})$ at time 0,1 and $2 \mathrm{~h}$. Data are presented as mean \pm SE. *: $\mathrm{p}<0.05$.

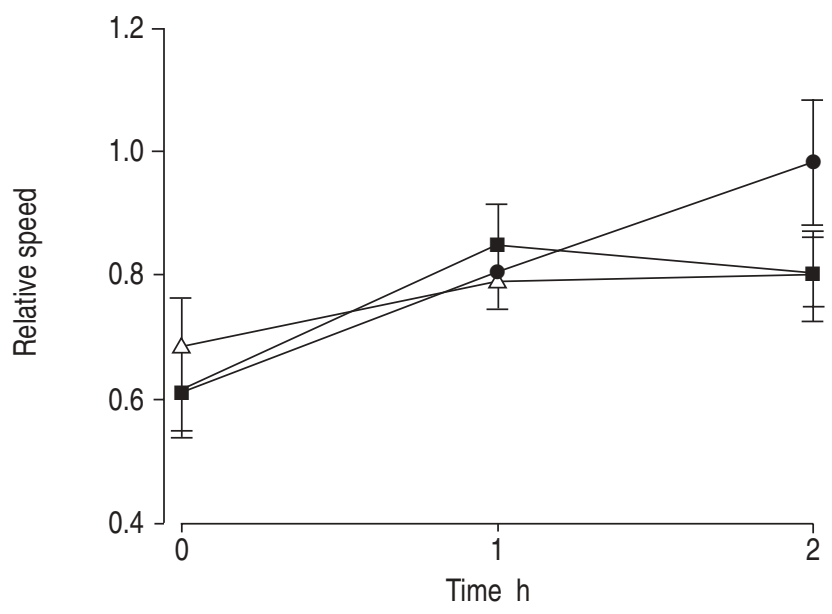

Fig. 2. - Results of the in vitro mucociliary transportability as relative speed in the control $(\bullet)$, furosemide+hypovolaemia $(\triangle)$ and furosemide+volume replacement (ם) groups at time 0,1 and 2. Data are presented as mean \pm SE. $n=12$ per group.

moderate hypovolaemia in the $\mathrm{F}+\mathrm{H}$ group. The inclusion of a group $(\mathrm{F}+\mathrm{R})$, in which volume replacement matched urine output, allowed the effects of furosemide and hypovolaemia to be separated. Furosemide, a potent $\mathrm{Cl}^{-}$secretion inhibitor in the respiratory epithelium, promoted a significant fall in PD only when associated with hypovolaemia. The present study provides evidence that volume status is an important variable contributing to the decrease in PD. As all the groups maintained normal plasma sodium along the study period, there was no unique relationship between plasma sodium and airway PD. This is evidence that hypovolaemia has an independent effect from changes in plasma sodium. These results occurred within an acute intervention with no significant changes in mucus properties among the groups.

The direction of net water flux across the tracheobronchial epithelium has been suggested to result from transepithelial ion transport with secondary osmotic water movement [7, 13]. PD variation might represent a mechanism for controlling water content within the airway via ion fluxes, which could be associated with modulation of mucus rheology and clearability [1]. PD is considered as an index of epithelium function $[1,4,7]$ and it has been used in the diagnosis of lung diseases like cystic fibrosis [3, 22] or in characterising pulmonary injury [1, 7]. Tracheal PD values were measured in the lower part of the opened trachea and mean values were $\sim-15 \mathrm{mV}$ in all groups at time $0 \mathrm{~h}$. These results fit with data reported by others in dogs [1] and in anaesthetised subjects [7]. PD remained stable along the study period in controls. In the current study, inhibition of the $\mathrm{NaK}(\mathrm{Cl})_{2}$ co-transporter by furosemide did not cause a marked decrease of tracheal PD, similar to a previous report [14]. Given the known effects of furosemide on epithelial bioelectric properties, a similar PD decrease should have been obtained in both groups that received identical furosemide dosing. However, an intermediate PD decrease was found in the $\mathrm{F}+\mathrm{R}$ group and a marked decrease in the $\mathrm{F}+\mathrm{H}$ group as compared to controls $(\mathrm{p}=0.011)$ (fig. 1). Plasma sodium remained within normal limits in all groups, and there was no unique relationship between plasma sodium and PD, indicating that this was not the reason for differences in PD behaviour among the two groups that received furosemide. As $\mathrm{PD}$ is a sensitive index of mucosal perfusion and function, the current authors have raised the possibility that hypovolaemia might have caused tracheal hypoperfusion, which in turn could have further decreased PD. ANEMAN et al. [23] showed a significant decrease in duodenal transepithelial PD after hypovolaemia, which was associated with critical reductions in mucosal perfusion.

The acute effects of furosemide on mucus properties and MCT have shown conflicting results. Furosemide is more effective from the serosal, than the luminal, side of the tissue $[12,24]$, and has been associated with the inhibition of basolateral-to-luminal water fluxes [14]. If $\mathrm{Cl}^{-}$flux is associated with water flux from mucosa into the lumen, then inhibition of $\mathrm{NaK}(\mathrm{Cl})_{2}$ co-transporter may reduce mucus water content and ultimately MCT. Consistent with this hypothesis, KoNDo et al. [10] showed a decrease in in vitro MCT in mechanically ventilated patients that received furosemide for up to $4 \mathrm{~h}$. On the contrary, WINTERS and YEATES [13] observed that furosemide (40 mg) increased in vivo $\mathrm{MCT}$ in dogs and baboons. These authors raised some

Table 3. - Mucus rheology (logarithm of $\mathrm{G}^{*}$, rigidity factor at 1 and 100 radians $\cdot \mathrm{s}^{-1}$, frequency of deformation) was evaluated in each group at time 0,1 and $2 \mathrm{~h}$

\begin{tabular}{|c|c|c|c|c|c|c|c|c|c|}
\hline \multirow[t]{2}{*}{ Time $\mathrm{h}$} & \multicolumn{3}{|c|}{$\mathrm{C}$} & \multicolumn{3}{|c|}{$\mathrm{F}+\mathrm{H}$} & \multicolumn{3}{|c|}{$\mathrm{F}+\mathrm{R}$} \\
\hline & 0 & 1 & 2 & 0 & 1 & 2 & 0 & 1 & 2 \\
\hline $\log \mathrm{G}^{*} 1 \mathrm{radian} \cdot \mathrm{s}^{-1}$ & $1.6 \pm 0.1$ & $1.3 \pm 0.1 *$ & $1.1 \pm 0.1 *$ & $1.8 \pm 0.1$ & $1.7 \pm 0.2 *$ & $1.7 \pm 0.2^{*}$ & $1.9 \pm 0.1$ & $1.4 \pm 0.2 *$ & $1.4 \pm 0.3^{*}$ \\
\hline Log $\mathrm{G}^{*} 100 \mathrm{radians} \cdot \mathrm{s}^{-1}$ & $1.7 \pm 0.1$ & $1.5 \pm 0.1$ & $1.4 \pm 0.1$ & $1.7 \pm 0.1$ & $1.8 \pm 0.2^{*}$ & $1.8 \pm 0.1^{*}$ & $1.8 \pm 0.1$ & $1.5 \pm 0.1$ & $1.7 \pm 0.1$ \\
\hline Tan $\delta 1 \mathrm{radian} \cdot \mathrm{s}^{-1}$ & $0.7 \pm 0.1$ & $0.5 \pm 0.1$ & $0.6 \pm 0.1$ & $0.6 \pm 0.1$ & $0.6 \pm 0$ & $0.5 \pm 0$ & $0.6 \pm 0$ & $0.5 \pm 0.1$ & $0.6 \pm 0.1$ \\
\hline Tan $\delta 100$ radians $\cdot \mathrm{s}^{-1}$ & $0.7 \pm 0.1$ & $0.7 \pm 0.1$ & $0.6 \pm 0.1$ & $0.6 \pm 0.1$ & $0.5 \pm 0.1$ & $0.8 \pm 0.1$ & $0.7 \pm 0.1$ & $0.7 \pm 0.1$ & $0.6 \pm 0.1$ \\
\hline
\end{tabular}

Data are presented as mean \pm SE. C: control; $\mathrm{F}+\mathrm{H}$ : furosemide+hypovolaemia; $\mathrm{F}+\mathrm{R}$ : furosemide+volume replacement; tan $\delta$ : tangent $\delta$ (ratio between viscosity and elasticity). *: mean values were different from controls $(p<0.05)$. 
potential mechanisms triggered by the diuretic that may have stimulated MCT, such as release of vasopressin and/or angiotensin, the inhibition of sensory nerves that regulate secretion, and the induction of microvascular leakage. Differences between studies could be related to the methodology. In vitro MCT only evaluates mucus transportability properties, while in vivo MCT may be affected by mucus, cilia and the mucus-cilia interactions. Differences between species may also be relevant. Ion transport and effects of furosemide in the airway have been studied most extensively in the dog's tracheal epithelium. Dog trachea is similar to human trachea in dimension and alveolar ventilation [25]. However, it has been established that the canine tracheal epithelium actively transports electrolytes, and its activity is largely that of $\mathrm{Cl}^{-}$ secretion with a small component of sodium absorption [4, $12-14,17]$. In human epithelium, sodium absorption is the major active ion transport across excised airway, and $\mathrm{Cl}^{-}$ secretion does not occur under basal conditions [3, 4, 7]. Therefore, the effects of furosemide could be, theoretically, different in dogs and humans. In the present study, no significant acute effects of furosemide and hypovolaemia on tracheal mucus properties and in vitro mucus transportability by cilia were observed. It is possible that effects on respiratory mucus could have been present if a longer period had been examined.

Anaesthesia, tracheostomy, MV and the use of a heat and moisture exchanger have all been related to reductions in MCT [18, 26-28]. However, in the current study, these factors were equally applied to all groups. Also, the animals were carefully allowed to attain haemodynamic and ventilatory stabilisation before random assignment in the present study. The current study protocol allowed us to distinguish the acute effects of furosemide and hypovolaemia on mucus properties.

One limitation of the present study which was observed, was that the three experimental groups showed a timedependent decrease in $\log \mathrm{G}^{*}$ at $1 \mathrm{rad} \cdot \mathrm{s}^{-1}(\mathrm{p}<0.001)$ and an increase in in vitro MCT $(\mathrm{p}<0.05)$. An artificial humidification system was employed for the inspired air that passively preserves the exhaled air-water content and heat. The current authors tried to avoid two situations: breathing dry air or breathing air with an additional water content provided by a heated water humidifying system $[18,29]$. In a previous study [18], in patients with acute respiratory failure submitted to $\mathrm{MV}$, the artificial nose, as compared to a heated water humidifier, promoted changes in mucus properties only after $72 \mathrm{~h}$ of MV. As dogs use the airway for evaporative cooling (panting) [6], the heat and moisture exchanger may have retained too much water [29]. In contrast, offering dry air during MV would be a model of little clinical relevance.

There is a general belief that hydration status may affect respiratory mucus properties. Although physiologically interesting, the effects of hydration and dehydration on respiratory mucus properties have received little attention. BANG and BANG [8], in an old study in chickens, demonstrated that severe dehydration, up to $72 \mathrm{~h}$, resulted in progressive deterioration of nasal mucociliary function, most probably due to viscid mucus. The nasal MCT dysfunction was reversed with spontaneous rehydration. CHOPRA et al. [9] found that $i$.v. saline solution $(0.9 \% \mathrm{NaCl})$ increased tracheal clearance rate in anaesthetised dogs. MARCHETTE et al. [30] showed that systemic hydration at volumes ranging from 5-35 $\mathrm{mL} \cdot \mathrm{kg}^{-1}$ did not significantly alter baseline tracheal mucociliary transport in the normal state of conscious sheep. However, in the allergic sheep airway, the volume infusion further impaired MCT. SHIM et al. [31] found no effects of fluid regimens, oral hydration and a modest dehydration, on volume sputum and rheological properties in patients with chronic bronchitis. The present study employed a model of dehydration induced by furosemide, which influences ion and water fluxes across the respiratory membrane by inhibition of $\mathrm{NaK}(\mathrm{Cl})_{2}$ co-transporter, as previously discussed. Nevertheless, no significant changes in mucus physical properties and transportability by cilia were observed, suggesting that the association of dehydration and furosemide has little or no effect on mucus properties in this acute experimental model. The current authors' interpretation is that the primary effect of hypovolaemia is directed towards peri-ciliary fluid hydration and only secondarily, if at all, towards mucus hydration.

In summary, furosemide promoted a nonsignificant decrease in potential difference by a direct inhibitory effect on the $\mathrm{NaK}(\mathrm{Cl})_{2}$ co-transporter located in the basolateral membrane of the tracheal epithelium. In contrast, furosemide, associated to intravascular volume depletion, decreased the potential difference significantly. These results indicate that, in addition to the direct effect of furosemide, hypovolaemia also affects ion transport in the tracheal membrane. However, these changes in potential difference were not associated with significant changes in mucus properties with up to $2 \mathrm{~h}$ of intervention. Acutely, furosemide and hypovolaemia have little or no effect on respiratory mucus properties or mucus transportability by cilia.

Acknowledgements. The authors would like to thank C. Timo-Iaria and A. Seguro for outstanding assistance and advice. The authors also wish to thank G. de Mello Nascimento, E. Tigre Guimarães, M. Macchione, R. Carvalho de Oliveira and H. Bueno Guimarães for excellent technical assistance, and J. Fukushima for helping with the statistical analysis.

\section{References}

1. App EM, Zayas JG, King M. Rheology of mucus and transepithelial potential difference: small airways versus trachea. Eur Respir J 1993; 6: 67-75.

2. Trout L, King M, Feng W, Inglis SK, Ballard ST. Inhibition of airway liquid secretion and its effect on the physical properties of airway mucus. Am J Physiol 1998; 274: 258-263.

3. Knowles MR, Stutts MJ, Yankaskas JR, Gatzy JT, Boucher RC. Abnormal respiratory epithelial ion transport in cystic fibrosis. Clin Chest Med 1986; 7: 285-297.

4. Tomkiewicz RP, Albers GM, De Sanctis GT, Ramirez OE, King M, Rubin BK. Species differences in the physical and transport properties of airway secretions. Can J Physiol Pharmacol 1995; 73: 165-171.

5. Nathanson I, Nadel JA. Movement of electrolytes and fluid across airways. Lung 1984; 162: 125.

6. Smith JJ, Welsh MJ. Fluid and electrolyte transport by cultured human airway epithelia. J Clin Invest 1993; 91: $1590-1597$.

7. Knowles MR, Buntin WH, Bromberg PA, Gatzy JT, Boucher RC. Measurements of transepithelial electric potential differences in the trachea and bronchi of human subjects in vivo. Am Rev Resp Dis 1982; 126: 108-112.

8. Bang BG, Bang FB. Experimentally induced changes in nasal mucous secretory systems and their effect on virus infection in chicken. J Exp Med 1969; 130: 105-140.

9. Chopra SK, Taplin GV, Simmons DH, Robinson GD, Elam D, Coulson A. Effects of hydration and physical therapy on tracheal transport velocity. Am Rev Respir Dis 1977; 115: 1009-1014.

10. Kondo CS, Nakagawa NK, Macchione M, King M, Saldiva PHN, Lorenzi-Filho G. Effects of intravenous furosemide in ICU patients under mechanical ventilation. Crit Care 2002; 6: $81-87$.

11. Iwasaki KI, Zhang R, Zuckerman JH, Pawelczyk JA, Levine BD, Blomqvist CG. Effect of head-down-tilt bed rest and 
hypovolemia on dynamic regulation of heart rate and blood pressure. Am J Physiol 2000; 279: 2189-2199.

12. Widdicombe JH, Nathanson IT, Highland E. Effects of "loop" diuretics on ion transport by dog tracheal epithelium. Am J Physiol 1983; 245: 388-396.

13. Winters SL, Yeates DB. Interaction between ion transporters and the mucociliary transport system in dog and baboon. J Appl Physiol 1997; 83: 1348-1359.

14. Phillips JE, Yeates DB. Bidirectional transepithelial water transport: chloride-dependent mechanisms. J Membr Biol 2000; 175: 213-221.

15. Knauf H, Haag $\mathrm{R}$, Lubcke $\mathrm{R}$, Berger E, Gerok W. Determination of short-circuit current in the in vivo perfused rat colon. Am J Physiol 1984; 246: 151-158.

16. Festa E, Guimarães E, Macchione M, Saldiva PHN, King M. Acute effects of uridine 5 '-triphosphate on mucociliary clearance in isolated frog palate. J Aerosol Med 1997; 10: 25-39.

17. Boucher RC, Stutts MJ, Gatzy JT. Regional differences in bioelectric properties and ion flow in excised canine airways. J Appl Physiol 1981; 51: 706-714.

18. Nakagawa NK, Macchione M, Petrolino HMS, et al. Effects of a heat and moisture exchanger and a heated humidifier on respiratory mucus in patients undergoing mechanical ventilation. Crit Care Med 2000; 28: 312-317.

19. King M, Macklem PT. Rheological properties of microliter quantities of normal mucus. J Appl Physiol 1977; 42: 797-802.

20. Silveira PSP, Böhm GM, Yang HM, Saldiva PHN. Computer assisted rheological evaluation of microsamples of mucus. Comput Methods Programs Biomed 1992; 39: 51-60.

21. Puchelle E, Tournier JM, Petit A. The frog palate for studying mucus transport velocity and mucociliary frequency. Eur J Respir Dis 1983; 74: 293-303.

22. Middleton PG, Guedes DM, Alton EWFW. Effects of amiloride and saline on nasal mucociliary clearance and potential difference in cystic fibrosis and normal subjects. Thorax 1993; 48: 812-816.

23. Aneman A, Pettersson A, Eisenhofer G, et al. Sympathetic and renin-angiotensin activation during graded hypovolemia in pigs: impact on mesenteric perfusion and duodenal mucosal function. Shock 1997; 8: 378-384.

24. Westenfelder C, Earnest WR, AL-Bazzaz FJ. Characterization of Na-K-ATPase in dog tracheal epithelium: enzymatic and ion transport measurements. J Appl Physiol 1980; 48: $1008-1019$.

25. Tenney SM, Bartlett DJ. Comparative quantitative morphology of the mammalian lung: trachea. Respir Physiol 1967; 3: 130-135.

26. King M, Engel LA, Macklem PT. Effect of pentobarbital anesthesia on rheology and transport of canine tracheal mucus. J Appl Physiol 1979; 46: 504-509.

27. Konrad F, Schreiber T, Grunert A, Clausen M, Ahnefeld FW. Measurement of mucociliary transport velocity in ventilated patients. Chest 1992; 102: 1377-1383.

28. Sackner MA, Hirsch J, Epstein S. Effect of cuffed endotracheal tubes on tracheal mucous velocity. Chest 1975; 68: 774-777.

29. Eckerbom B, Lindholm CE, Mannting F. Mucociliary transport with and without the use of a heat and moisture exchanger. An animal study. Acta Anaesthesiol Scand 1991; 35: 297-301.

30. Marchette LC, Marchette BE, Abraham WM, Wanner A. The effect of systemic hydration on normal and impaired mucociliary function. Pediatr Pulmonol 1985; 1: 107-111.

31. Shim S, King M, Williams MH. Lack of effect of hydration on sputum production in chronic bronchitis. Chest 1987; 92: 679-682. 